The effects of an imagery intervention on implicit and explicit exercise attitudes

Markland, D.A.; Markland, D.; Hall, C.R.; Duncan, L.R.; Simatovic, J.

\title{
Psychology of Sport and Exercise
}

DOI:

10.1016/j.psychsport.2014.11.007

Published: 04/12/2014

Peer reviewed version

Cyswllt i'r cyhoeddiad / Link to publication

Dyfyniad o'r fersiwn a gyhoeddwyd / Citation for published version (APA):

Markland, D. A., Markland, D., Hall, C. R., Duncan, L. R., \& Simatovic, J. (2014). The effects of an imagery intervention on implicit and explicit exercise attitudes. Psychology of Sport and Exercise, 17, 24-31. https://doi.org/10.1016/j.psychsport.2014.11.007

\footnotetext{
Hawliau Cyffredinol / General rights

Copyright and moral rights for the publications made accessible in the public portal are retained by the authors and/or other copyright owners and it is a condition of accessing publications that users recognise and abide by the legal requirements associated with these rights. study or research

- Users may download and print one copy of any publication from the public portal for the purpose of private

- You may not further distribute the material or use it for any profit-making activity or commercial gain

- You may freely distribute the URL identifying the publication in the public portal?
}

Take down policy

If you believe that this document breaches copyright please contact us providing details, and we will remove access to the work immediately and investigate your claim. 
The effects of an imagery intervention on implicit and explicit exercise attitudes

\author{
Manuscript accepted 10.11.14 \\ Psychology of Sport and Exercise
}

Markland, D., Hall, C., Duncan, L., \& Simatovic, J. (2015). The effects of an imagery intervention on implicit and explicit exercise attitudes. Psychology of Sport and Exercise, 17, 24-31.

http://dx.doi.org/10.1016/j.psychsport.2014.11.007

\author{
David Markland ${ }^{\mathrm{a}}$ \\ Craig R. Hall ${ }^{\mathrm{b}}$ \\ Lindsay R. Duncan ${ }^{\mathrm{c}}$ \\ Jacqueline Simatovic $^{\mathrm{b}}$ \\ ${ }^{a}$ School of Sport, Health \& Exercise Sciences, \\ Bangor University \\ George Building \\ Holyhead Road \\ Bangor, Gwynedd, LL57 2PZ, UK \\ ${ }^{\mathrm{b}}$ School of Kinesiology \\ Western University \\ Room 4161, Thames Hall \\ London, Ontario, Canada, N6A 5B9 \\ ${ }^{\mathrm{c}}$ Department of Kinesiology \& Physical Education \\ McGill University \\ 475 Pine Avenue West \\ Room 213, Montreal, Quebec \\ Canada H2W 1S4
}




\begin{abstract}
Objectives: This study examined the effects of exercise imagery on implicit and explicit attitudes towards exercise and the moderating effect of exercise status. It was predicted that exercise imagery would activate a pattern of positive automatic associations with exercise that would be reflected in more positive implicit attitudes. Corresponding effects were expected for explicit affective attitudes, but imagery was not expected to influence explicit instrumental attitudes.
\end{abstract} Design: A post-test only comparison group design.

Method: Participants $(N=160 ; 40$ male and 40 female frequent exercisers, 40 male and 40 female less frequent exercisers) were randomly allocated, stratified by exercise status and gender, to undergo either guided imagery of a pleasant experience of exercising or a comparison imagery condition. Participants then completed an Implicit Association Test, measures of explicit affective and instrumental attitudes, and an imagery manipulation check.

Results: There were significant main effects for experimental condition and exercise status on implicit attitudes, with more positive attitudes in the exercise imagery condition and for more frequent exercisers. There were significant main effects for exercise status on explicit affective and instrumental attitudes. Exercise status did not moderate the effects of imagery on implicit or explicit attitudes.

Conclusion: This is the first study to demonstrate that implicit attitudes to exercise can be modified, although only immediate effects were assessed. Future research should assess the generalisability of the findings in less active populations and examine the effects of repeated imagery on implicit attitudes to determine whether it could have more lasting effects and impact on actual exercise behaviour.

Keywords: Implicit Association Test; Associative and propositional evaluation model; Dual process models. 
Imagery and implicit exercise attitudes 3 
Understanding the determinants of exercise adoption and maintenance is a major focus of research in exercise and health psychology. The study of attitudes towards physical activity has been prominent in this research (Hagger, Chatzisarantis, \& Biddle, 2002). The majority of this research has been framed within the context of value-expectancy models such as the theory of planned behaviour (Ajzen, 1985) which posit that attitudes are determined by conscious, deliberative consideration of the benefits and costs associated with engaging in a behaviour and the personal value placed upon the outcomes of the behaviour. Advances in social cognition, however, have highlighted the importance of automatic or non-conscious cognitive processes in determining behaviour. A number of dual-process models of social cognition have been elaborated (e.g., Bargh \& Chartrand 1999; Fazio, 1990; Gawronski \& Bodenhausen, 2006; Strack \& Deutsch, 2004; Wilson, Lindsey, \& Schooler, 2000). The common feature of these models is the proposition that both explicit (consciously controlled) and implicit (automatically activated) cognitive processes, including attitudinal, self-concept, and motivational processes, can play a role in determining behaviour. Explicit processes are those that are rational and deliberative, effortfully initiated, accessible to awareness, and can be assessed by self-report measures. Implicit processes are automatically activated in response to contextual stimuli and are not deliberately initiated or controlled by the individual. The extent to which implicit cognitions are accessible to consciousness is a matter of some debate (Payne \& Gawronski, 2010), but there is a general agreement in the field of implicit social cognition that they are at best not readily amenable to accurate introspection, and so they cannot easily be assessed directly by self-report. Instead, implicit cognitions are typically measured indirectly using response latency paradigms. For example, the widely used Implicit Association Test (IAT: Greenwald, McGhee, \& Schwartz, 1998) is used to infer implicit attitudes by measuring the strengths of associations between target concepts and valence attributes through the speed with which individuals respond to pairings of concept exemplars and positive and negative attributes. 
There is a relative paucity of research on the role of implicit cognitive processes in physical activity. However, there are theoretical reasons to expect that implicit cognitive processes are involved in physical activity (Dimmock \& Banting, 2009) and the limited available empirical evidence does suggest that implicit cognitions are related to exercise behaviour. Eves, Scott, Hoppé, and French (2007) and Calitri, Lowe, Eves, and Bennett (2009) found that higher levels of physical activity were associated with positive implicit attitudes to exercise. Banting, Dimmock, and Lay (2009) found that implicit and explicit exercise schema explained similar amounts of variance in exercise behaviour. Conroy, Hyde, Doerksen, and Ribeiro (2010) found that implicit attitudes to physical activity prospectively predicted physical activity behaviours, objectively assessed by pedometer, after controlling for explicit motivational variables. Studies have also shown that implicit cognitions are associated with exercise-related cognitive and attentional processes. For example, Harju and Reed (2003) found that implicit exercise attitudes are associated with the importance placed on being an exerciser and avoiding being a non-exerciser. Similarly, Berry, Spence, and Clark (2011) found that exercise schematics (individuals who explicitly identify themselves as exercisers) had a stronger positive implicit bias toward exercisers than non-schematics. Scott, Eves, Hoppé, and French (2009) found that among regular exercisers, positive implicit beliefs about physical activity outcomes were more accessible than control outcomes. Finally, Calitri et al. (2009) found that implicit but not explicit exercise attitudes were associated with an automatic attentional bias towards exercise cues.

An important issue regarding implicit cognitions is the extent to which they are modifiable. Implicit attitudes are considered to reflect associations in memory that develop over time with repeated exposure to specific experiences. Consequently, it has been thought that they are relatively resistant to change through explicit interventions or verbal cues (Bargh, 1999). However, a number of studies have now shown that implicit cognitions can be modified, even by brief interventions, at least in the short term. Of particular relevance to the current study, across 
five studies Blair, Ma, and Lenton (2001) weakened implicit gender stereotypes by having participants engage in a brief counterstereotypic mental imagery exercise in which they were asked to imagine a strong woman. The authors argued that mental imagery, even though it is intentional and controlled, can moderate implicit processes because it increases the accessibility of related cognitive, emotional, and behavioural representations in memory. Thus, imagining a strong woman activated pre-existing but normally less accessible memories of actual strong women and their related positive attributes, leading to an attenuation of typical implicit gender stereotyping. Blair et al. (2001) suggested that imagery may be a particularly powerful method of influencing implicit cognitions because of the similarity of imaged experience to actual perceptual experience.

Gawronski and Bodenhausen's (2006) associative and propositional evaluation (APE) model offers a further theoretical rationale for the potential for imagery to modify implicit attitudes. According to this model, implicit and explicit attitude measures reflect two distinct forms of evaluative processes: associative and propositional processes. Associative processes are defined as the momentary activation of patterns of association in memory. Propositional processes are defined as the conscious validation (the subjective truth or accuracy) of momentarily activated patterns of association. Contextual cues can activate different subsets of patterns of automatic associations from the available associations in memory. Thus, a contextual factor, such as engaging in imagery of an attitude object, could be manipulated to elicit positive (or indeed negative) automatic evaluations of the object, provided that there are pre-existing positive (or negative) associations in memory. Such changes in pattern activation can lead to rapid changes in implicit attitude measures (Rydell \& McConnell, 2010). Indeed, according to the APE model, positive associative evaluations can be activated regardless of whether a person consciously endorses these evaluations (Gawronski \& Bodenhausen, 2006). In support of this, Foroni and Mayr (2005) reversed the classic flowers/insects IAT effect (the ubiquitous implicit preference for flowers over insects) by presenting participants with a short written scenario describing a post- 
apocalyptic world in which flowers have become noxious to humans whereas insects have become a crucial source of food.

The APE model also specifies conditions under which contextual manipulations will modify responses to implicit but not explicit measures, explicit but not implicit measures, or both (Gawronski \& Bodenhausen, 2006). Because the activation of associative processes is independent of their subjective validation, an intervention like imagery of a pleasant experience of exercise might temporarily activate a pattern of positive automatic evaluative associations with exercise, which would be reflected in positive responses to an implicit measure of attitudes. Momentarily activated automatic associations typically serve as the basis for explicit evaluations (Gawronski \& Srithara, 2010). However, when motivated to consciously consider one's attitudes (e.g., by completing a self-report measure), these automatically activated associations may be rejected if they are inconsistent with other considered information, resulting in a lack of impact on an explicit measure of attitudes. Dasgupta and Greenwald (2001) found such a dissociation in two studies examining racial and age-related attitudes. Presentation of visual images of well-known admired exemplars of black and older people modified implicit attitudes, assessed by an IAT, but had no influence on explicit attitudes.

The likelihood of a dissociation between implicit and explicit measures depends, in part, on the degree of cognitive elaboration in the propositional evaluation of an attitude object (Hofmann, Gschwendner, Nosek, \& Schmitt, 2005a). Thus the method of assessing explicit attitudes could influence the correspondence between implicit and explicit attitudes. Implicit measures have been characterised as reflecting affective rather than cognitive components of attitudes (Hofmann et al., 2005a) and greater consistency has been observed between explicit measures and IAT scores when the explicit measures assess affective rather than cognitive responses (Hofmann, Gawronski, Gschwendner, Le, \& Schmidt, 2005b). Thus, a manipulation that influences implicit attitude scores may also influence responses to an affective explicit 
attitude measure but not a cognitive explicit measure requiring greater cognitive elaboration, such as an evaluation of the instrumental value of the attitude object.

The aim of the current study was to examine the effects of guided imagery on implicit and explicit attitudes to exercise. Based on the idea that engaging in a mental imagery exercise focused on imagining a pleasant experience of exercising would activate positive automatic associations with exercise, we hypothesised that pleasant exercise imagery would lead to a more positive implicit attitude toward exercise than a comparison imagery condition. Due to the greater consistency between affective rather than cognitive explicit attitude measures and implicit measures, we also predicted that pleasant exercise imagery would lead to more positive affective explicit attitudes to exercise but would not influence instrumental explicit attitudes.

A further consideration in the current study was to examine the extent to which the effects of exercise imagery on implicit and explicit attitudes might be moderated by exercise status. According to the APE model, the momentary activation of a positive subset of patterns of automatic evaluative associations with exercise would depend upon such positive patterns preexisting in memory (Gawronski \& Sritharan, 2010). It is likely that few individuals will have had such a negative history of experiences with exercise that they have no pre-existing positive evaluative associations at all. However, attitude formation and accessibility are influenced by direct experience (Fazio \& Zanna, 1981; Fazio, Chen, \& Sherman, 1982). Therefore, more regular exercisers may have more accessible positive automatic associations with exercise than less regular exercisers. As noted earlier, previous research has shown that higher physical activity levels are associated with more positive implicit attitudes to exercise (e.g., Calitri et al., 2009). Therefore, we predicted that exercise status (frequent versus less frequent engagement) would moderate the effects of imagery on implicit exercise attitudes, with a greater effect among more frequent exercisers. Corresponding effects were predicted for affective explicit attitudes but, given 
that we predicted no impact of imagery on instrumental attitudes, we expected only a main effect of exercise status on instrumental attitudes.

\section{Methods}

\section{Design}

The study employed a post-test only comparison group design.

\section{Participants}

One hundred and sixty participants completed the study $(M$ age $=23.03, S D=4.83)$. The participants were either undergraduate $(87.2 \%)$ or postgraduate students. Participants were initially categorised as either more frequent exercisers (reported exercising at least three times a week at a moderate intensity for the past 6 months) or less frequent exercisers (reported exercising two or fewer times a week for the past 6 months). There were 40 male and 40 female frequent exercisers, and 40 male and 40 female less frequent exercisers. Participants were randomly assigned to either an experimental guided imagery condition or a comparison guided imagery condition using a computer-generated list of random numbers whilst maintaining equal numbers of males and females and more frequent and less frequent exercisers in each condition.

\section{Measures}

Physical activity

Current physical activity was assessed with the Leisure Time Exercise Questionnaire (LTEQ: Godin \& Shephard, 1985). Respondents indicate the frequency of mild, moderate, and strenuous exercise undertaken in a typical week. Scores are weighted by approximate metabolic equivalents (METs) for the different levels of activity $(3,5$, and 9 respectively) and summed to produce a total weekly exercise score, expressed in METs. Studies have shown LTEQ scores to have adequate reliability and validity with respect to objective assessments of exercise behaviour

and indices of fitness (e.g., Jacobs, Ainsworth, Hartman, \& Leon, 1993). Participants also reported the number of years that they had been regularly physically active. 


\section{Implicit attitudes}

Implicit attitudes towards exercise were assessed using the Implicit Association Test (IAT:

Greenwald, McGhee, \& Schwartz, 1998). The IAT is a computerised method for indirectly assessing implicit attitudes by measuring the strengths of associations among concepts through the speed with which individuals respond to the presentation of stimuli associated with the concepts. The logic of the IAT is that the more favourable a participant's implicit attitude toward a target category (e.g., exercise), the stronger the association in memory between exemplars of the target (e.g., images of people exercising) and positive evaluative words (e.g., good) and the weaker the association with negative evaluative words (e.g., bad). Therefore participants with a positive implicit attitude to exercise will respond faster to target exemplars paired with positive attribute words and slower to exemplars paired with negative attribute words.

The Inquisit 3.0 software suite (Millisecond Software, 2008), which presents stimuli on a computer screen and records response latencies to keyboard presses with millisecond accuracy, was used to generate the IAT and collect the data. The target categories were labeled 'Exercise' and 'Not Exercise' with target exemplars comprising colour photographic images of individuals engaging in exercise in a gym or indoor environment (running on a treadmill, stretching, performing resistance exercise, using an exercise ball) or sedentary activities (reading a book, watching television, resting), respectively. Male and female participants completed male and female image versions of the test, respectively. The evaluative categories were labeled 'Pleasant' and 'Unpleasant' with exemplars comprising positive words (e.g., 'marvelous') and negative words (e.g., 'awful'). There were nine exemplar images and eight evaluative words in each category. The images and words are available from the first author on request.

A pilot study with was conducted in order to ensure that the exercise and sedentary exemplar images were not simply rated as more or less pleasant. In a classroom environment, the images were presented to 41 female $(M$ age $=20.12, S D=3.82)$ and 59 male $(M$ age $=19.97, S D$ 
$=3.77$ ) undergraduate students in random order on a large screen for 5 seconds each, interspersed with 24 images of landscapes, animals and buildings. Participants rated the extent to which they found each image pleasant or unpleasant on a 7-point scale ranging from -3 (very unpleasant), through zero (neither pleasant nor unpleasant), to +3 (very pleasant). There were no significant differences $(t(41)=1.17, p=.25)$ in female participants' ratings of the female exercise images $(M$ $=0.09, S D=0.77,95 \%$ bias corrected and accelerated bootstrapped $(\mathrm{BCa}) \mathrm{CI}[-0.16,0.31])$ and sedentary images $(M=0.01, S D=0.75,95 \%$ BCa CI $[-0.21,2.0])$, nor in male participants' ratings $(t(58)=.21, p=.84)$ of the male exercise images $(M=-0.44, S D=0.76,95 \%$ BCa CI $[-0.64,-$ $0.27])$ and sedentary images $(M=-0.46, S D=0.89,95 \%$ BCa CI $[-0.69,-0.24])$.

The IAT was presented on a personal computer in seven blocks, three of which were practice blocks (20 trials each) to acquaint participants with the categorisation rules. Prior to each block, instructions were presented on the screen. If participants made an error on a trial, an X appeared on screen and they were required to make a correct response before moving on to the next stimulus presentation. The critical test blocks were the third and fourth blocks (20 and 40 trials respectively), labeled compatible blocks, where exercise exemplars were paired with positive evaluative words on one response key and the not-exercise exemplars with the negative evaluative words on another response key, and the sixth and seventh blocks (20 and 40 trials respectively), labeled incompatible blocks, in which these pairings were reversed. Exercise and not-exercise exemplars and evaluative stimuli were presented randomly without replacement within blocks, independently for each participant. Order of presentation of compatible and incompatible blocks was counterbalanced across participants. Trials were separated by a $250 \mathrm{~ms}$ inter-trial interval. Response latencies were recorded for the test block trials and an IAT score computed from the difference between performance on the compatible and incompatible test trials using the $D$-score algorithm for IAT data (Greenwald, Nosek, \& Banaji, 2003). Higher positive scores indicate a more favourable implicit attitude to exercise relative to the contrast category. Adopting standard 
IAT procedures, trials with latencies greater than $10000 \mathrm{~ms}$ were eliminated from the data (five trials) and cases with more than $10 \%$ of trial response latencies less than $300 \mathrm{~ms}$ were eliminated (six cases) prior to data analysis.

\section{Explicit Attitudes}

Explicit attitudes towards exercise were assessed using Courneya and Bobick's (2000) 7point bipolar adjectival rating scale that assesses instrumental (useful - useless, harmful beneficial, wise - foolish, good - bad) and affective (enjoyable - unenjoyable, interesting boring, pleasant - unpleasant, relaxing - stressful) components of attitude towards exercise. Participants are asked to rate each item using the following stem: 'For me to participate in regular physical exercise is...'. Separate mean scores were calculated for the instrumental and affective items.

\section{Imagery manipulation check}

In order to ensure that any observed effects for the imagery conditions were not due to differential ease or vividness of imagery, participants completed post-test measures of ease and vividness of imagery (How easy was it for you to create clear images in your head as you listened to the imagery script?; How easy was it for you to feel the images that were described to you in the imagery script?; How easy was it for you to involve your other senses (smell, taste, hearing) as you listened to the imagery script?). Participants rated their responses on a seven-point scale ranging from 'Very difficult' to 'Very easy'.

\section{Procedures}

The study protocol was reviewed and approved by an institutional research ethics panel. Participants were recruited through visits to university classes and by word of mouth. The researchers described the study and interested participants provided contact information. Potential participants were screened for exercise status and categorised according to whether they were frequent or less frequent exercisers, and a time for testing was arranged. At the beginning of the 
experimental sessions, participants gave informed consent, provided demographic data, and completed the LTEQ. Before undergoing the guided imagery, participants were asked to read a short script describing the nature of imagery. Participants then listened to their assigned audiorecorded imagery script. Participants in the experimental group received guided imagery of a visit to a fitness facility, and participants in the comparison group received guided imagery of preparing and eating a meal at the end of the day. Both scripts (see Appendix) were approximately 3 minutes long, guided participants to focus on positive sensations associated with the respective activities, and were informed by recommendations provided by Williams, Cooley, Newell, Weibull, and Cumming (2013) on the development of imagery scripts. The exercise script was prepared using the same procedure as imagery scripts we had employed in previous research. To guide participants to use a range of sensory modalities, we included text that would prompt multiple sensory experiences (e.g., sights, sounds, feeling muscles getting warmed up) as well as emotional experiences (e.g., enjoying the experience). We sought to be specific enough that the participants would be prompted for each of these experiences but vague enough that they could personalize the imagery experience. For the control script we wanted to describe an experience that would elicit similar sensory and emotional experiences to the exercise script and chose meal preparation because most people are familiar with this task and would be readily able to image it. Further details on how the scripts were developed are available from the first author on request. Participants then completed the IAT. Next, participants completed the explicit attitudes scales and the imagery manipulation check.

\section{Results}

To assess the reliability of the IAT $D$-scores, compatible trial latencies and incompatible trial latencies were split into odd and even numbered trials and split-half reliability coefficients with the Spearman-Browne correction were calculated. Results showed good reliabilities in both cases (compatible trials $\rho=.91, p<.001$; incompatible trials $\rho=.93, p<.001$ ). The instrumental 
and affective explicit attitude measures also had acceptable internal consistencies (Cronbach's alphas $=.80$ and .86 respectively).

The bivariate correlation between instrumental and affective explicit attitudes was $r=.69$ $(p<.001 ; 95 \%$ (BCa) CI [.61,.76]). The bivariate correlations between implicit attitudes and instrumental and affective explicit attitudes were $r=.24(p<.001 ; 95 \%$ BCa CI $[.09, .40])$ and $r=$ $.32(p<.001 ; 95 \%$ BCa CI $[.17, .46])$, respectively. There was no significant difference between these two correlations (Fisher's $z=1.19, p=.24$ ).

\section{Exercise status and manipulation checks}

Three-factor ANOVAs with self-reported number of years exercising, total exercise, strenuous, moderate, and mild exercise, and age as dependent variables were conducted. The assumptions underpinning factorial ANOVAs were satisfied. There were no main effects for experimental condition or gender and no two- or three-way interactions, indicating that randomisation had been successful with regard to these variables. Table 1 shows descriptive statistics for exercise frequency by exercise status. Participants categorised as frequent exercisers scored significantly higher than less frequent exercisers on total exercise $(F(1,152)=328.25, p<$ $.001, \eta^{2}=.79$, Cohen's $\left.d=2.82\right)$, strenuous exercise $\left(F(1,152)=114.14, p<.001, \eta^{2}=.84\right.$, Cohen's $d=1.67)$, moderate exercise $\left(F(1,152)=19.26, p<.001, \eta^{2}=.51\right.$, Cohen's $\left.d=0.70\right)$ and mild exercise $\left(F(1,152)=18.76, p<.001, \eta^{2}=.44\right.$, Cohen's $\left.d=0.69\right)$. Frequent exercisers also reported having exercised regularly for significantly more years (frequent $M=11.83, S D=5.47$, 95\% CI $[10.65,12.99] ;$ less frequent $M=4.34, S D=5.27,95 \%$ CI $[3.17,5.51] ; F(1,152)=79.64, p$ $<.001, \eta^{2}=.33$, Cohen's $d=1.39$ ). These large differences indicate a clear separation by the initially assigned exercise status. A one-way MANOVA with the imagery manipulation check items as dependent variables showed no significant differences between experimental and comparison conditions $(F(3,156)=1.09, p=.36)$, indicating no differences in ease or vividness of imagery in the two conditions. 


\section{$\underline{\text { Insert Table } 1 \text { about here }}$}

\section{Intervention effects}

Table 2 shows descriptive statistics for the attitude measures by imagery condition and exercise status. Because participants completed matched gender IATs, initial three-way ANOVAs were conducted including gender as an independent variable (experimental condition $\times$ exercise status $\times$ gender). No gender effects were observed and so intervention effects were analyzed by two-factor ANOVAs (imagery condition $\times$ exercise status). The assumptions underpinning factorial ANOVAs were met. For IAT $D$-scores there were significant main effects for experimental condition $\left(F(1,150)=6.53, p=.01, \eta^{2}=.04\right)$ and exercise status $(F(1,150)=13.63$, $\left.p<.001, \eta^{2}=.08\right)$. The condition $\times$ status interaction was not significant $(F(1,150)=0.27, p=.60$, $\left.\eta^{2}=.00\right)$. The exercise imagery group scored higher than the comparison imagery group (Cohen's $d=0.39$ ) and the frequent exercisers scored higher than less frequent exercisers (Cohen's $d=$ 0.57). For affective explicit attitudes there was a significant main effect for exercise status $\left(F(1,156)=70.59, p<.001, \eta^{2}=.31\right)$. The main effect for experimental condition $(F(1,156)=$ $\left.0.41, p=.52, \eta^{2}=.00\right)$ and the condition $\times$ status interaction $\left(F(1,156)=2.27, p=.13, \eta^{2}=.01\right)$ were not significant. The frequent exercisers scored higher than infrequent exercisers (Cohen's $d=$ 1.94). For instrumental explicit attitudes there was a significant main effect for exercise status $\left(F(1,156)=48.37, p<.001, \eta^{2}=.23\right)$. The main effect for experimental condition $(F(1,156)=$ $\left.2.88, p=.09, \eta^{2}=.01\right)$ and the condition $\times$ status interaction were not significant $(F(1,156)=2.40$, $\left.p=.12, \eta^{2}=.01\right)$. The frequent exercisers scored higher than infrequent exercisers (Cohen's $d=$ $1.31)$.

\section{$\underline{\text { Insert Table } 2 \text { about here }}$}

\section{Discussion}

The aims of this study were to examine the effects of guided pleasant exercise imagery on implicit and explicit attitudes to exercise and the moderating effect of exercise status on the effects 
of exercise imagery. Before considering the results, it should be noted that they need to be interpreted in the light of the post-test only comparison group design employed. The design was chosen in order to avoid reactive effects of testing. However, we have no way of knowing whether the attitude measures actually changed in response to the experimental treatments and can only interpret the results in terms of differences between the exercise imagery and the comparison condition. Given that randomisation was effective in equating the groups with regard to exercise levels and age, it seems reasonable to assume that it was also effective with regard to implicit and explicit exercise attitudes and it may be reasonable to assume that the comparison imagery condition would have had little or no impact on either implicit or explicit attitudes. Therefore, differences in attitude scores in the exercise imagery condition relative to the comparison condition might reflect pre- to post-test changes. Nevertheless, we confine our interpretation of the results to the effects of the exercise imagery relative to the comparison imagery.

\section{Implicit attitude effects}

Based on Gawronski and Bodenhausen's (2006) APE model, our first prediction was that engaging in imagery of a pleasant exercise experience would activate a pattern of positive automatic associations with exercise which would be expressed in more positive responses to the implicit measure. It was also predicted that the effect of exercise imagery would be moderated by exercise status because positive associative patterns would be more accessible in more frequent exercisers. The findings showed a moderately sized main effect of imagery condition and a larger sized main effect of exercise status, with more positive scores in the exercise imagery condition and for more frequent exercisers. The expected moderating effect for exercise status did not emerge, indicating that the effects of pleasant exercise imagery led to more positive implicit attitude scores relative to the comparison imagery, regardless of exercise status. This is likely because, although there were large differences in current exercise levels and years of regular exercise between the frequent and less frequent exercisers, those designated 'less frequent' still 
reported being, on average, quite active and had been so for more than four years. If the automatic associative pattern activation rationale for our hypothesis is correct, it seems that positive associations with exercise were readily accessible even among the less active individuals. A moderating effect of exercise status might be found if frequent exercisers were compared with sedentary individuals.

\section{Explicit attitude effects}

With regard to explicit attitudes, we predicted that the effects of exercise imagery on affective attitudes would correspond to those for implicit attitudes but that there would only be a main effect for exercise status on instrumental attitudes. Instead, there were only main effects of status on both affective and instrumental attitudes. The hypothesised lack of an effect of imagery on instrumental attitudes, based on the idea that responses to instrumental items would involve greater cognitive elaboration, was therefore supported, but considering the results together with those for affective attitudes this finding should be treated with caution for several reasons. The two explicit measures were highly correlated. This lack of differentiation between the measures is likely to have limited the possibility of finding differential effects of imagery. The expected corresponding effect for implicit and explicit affective attitudes was based on the findings of greater consistency between explicit measures and IAT scores when the explicit measures assess affective rather than cognitive evaluations (Hofmann et al., 2005a). In the present study however, the correlations between the two explicit measures and the IAT were not significantly different, again indicating a lack of differentiation in the two measures. Hofmann and colleagues' finding of greater consistency between affective measures and IAT scores was based on a meta-analysis across a wide range of domains, a variety of cognitive measures were included, many of which were trait-ratings, and the actual magnitude of the difference in the correlations was not large (affective $\rho=.28$, cognitive $\rho=.18$ ). In the present study, the affective and instrumental items were intermingled and presented together, which in itself is likely to have contributed to the strong 
correlation between them and to the failure to find greater correspondence between intervention effects on affective and implicit attitudes. Taken together, the pattern of observed correlations among the explicit and implicit measures in the current study indicates that the affective and instrumental items were responded to in a similar manner and suggests that the instrumental items did not require more cognitive elaboration than the affective items.

This then leaves the question as to why imagery had no impact on either component of explicit attitudes. This lack of an effect contrasts markedly with recent research which has shown effects of imagery interventions on explicitly assessed exercise-related affect (Stanley \& Cumming, 2010), motivation (e.g., Andersson \& Moss, 2011; Chan \& Cameron, 2012; Duncan, Hall, Wilson, \& Rodgers, 2012; Giacobbi, Dreisbach, Thurlow, Anand, \& Garcia, 2014) and selfefficacy (Duncan, Rodgers, Hall, \& Wilson, 2011). The lack of an effect for imagery on explicit attitudes may be due to limitations in the measurement of the explicit attitudes. Scores on instrumental attitudes were close to the maximum scale point and affective attitude scores were well above the scale mid-point. Previous authors (e.g., Courneya, Conner, \& Rhodes, 2006) have noted that scores on measures of attitudes to socially-desirable health behaviours, including exercise, are often very high and exhibit low variability, and can therefore suffer from ceiling effects. Furthermore, according to the APE model, explicit evaluative judgments can be influenced by propositions referring to general beliefs about the world (Gawronski \& Bodenhaus, 2006) and exercise is generally regarded as a positive behaviour (Banting et al., 2009). Thus, participants may have been responding with regard to general beliefs about exercise (i.e., 'it is a good thing'). Although in the current study the effect sizes for exercise status were very large, indicating that the explicit scales could discriminate well between more and less frequent exercisers, ceiling effects, social-desirability concerns, or general beliefs about exercise may have limited the ability to detect any impact of imagery on explicit attitudes.

\section{Implications and future directions}


The findings from this study add to the literature demonstrating that brief interventions can lead to changes in implicit cognitions and are interpretable in terms of the APE model. However, we only examined the immediate effects of imagery on implicit attitudes. It is very unlikely that the manipulation would have lasting effects. Therefore a brief imagery intervention such as this is not likely to impact on actual behaviour. According to the APE model, changes in automatic associative evaluations may result from temporal changes in pattern activation (as we assume happened in the current study) or from longer term incremental changes in underlying associative structures. In order to facilitate more positive implicit exercise attitudes, and thereby increase the likelihood of sustained and regular engagement, such structural changes would depend upon repeated and consistent positive experiences of exercise. Imagery may be able to help in this regard. First, engaging in imagery immediately prior to exercising may temporarily activate positive automatic evaluations, making the actual experience of exercising more pleasurable. Second, according to Gawronski and Bodenhaus (2006), the prototypical example of interventions that produce changes in associative structures is evaluative conditioning, whereby an attitude object is repeatedly paired with a positive or negative stimulus. Repeated pairings of the concept of exercise with pleasant sensations through engagement in imagery could be a form of evaluative conditioning which, over time, would lead to positive changes in associative structures, particularly given the similarities between imagined experience and actual experience (Blair et al., 2001; Lang, 1979). Interventions that have employed repeated exposure to positive exercise imagery have shown changes in self-efficacy (Duncan et al., 2011), motivation (Chen \& Cameron, 2012; Duncan et al., 2012; Giacobbi et al., 2014) and exercise behaviour (Chen \& Cameron, 2012). Although speculative, it may be that the effects of imagery in these studies were mediated in part by temporal or structural changes in associative structures. Longitudinal studies examining the effects of repeated imagery bouts on implicit attitudes are required to determine whether this is the case. 


\section{Limitations}

Apart from the lack of a pre-test measure in the study, there are three further main limitations. The first concerns the nature of the sample. Although we compared more frequent exercisers with less frequent exercisers, the less frequent exercisers were quite active. Therefore the findings cannot be generalised to inactive individuals or exercise initiates, the populations that, from a public health perspective, are most in need of effective interventions. If the observed effects of exercise imagery on implicit attitudes are due to the activation of pre-existing patterns of positive associations with exercise, it is likely to be more difficult to elicit such associations among sedentary individuals for whom positive associations are probably less readily accessible. One approach that might be effective would be to guide individuals to recall an actual positive or pleasant autobiographical experience of exercise. Biondolillo and Pillemer (2014) recently employed a memory-based intervention to increase exercise. Participants instructed to recall and write about a specific positive exercise experience reported engaging in significantly more exercise over a one week period than control participants, even though none reported having used the memory to motivate themselves to exercise. The authors suggested that future studies should assess the effects of regularly activating emotional memories as a motivational tool for exercise, particularly for those actively seeking to improve their health and fitness. Similarly, repeated engagement in imagery of actual positive exercise experiences might be a more effective method of changing implicit attitudes to exercise among inactive individuals and exercise initiates than engaging in imagery of a hypothetical experience.

A further potential limitation of the current study lies in the measure used to assess implicit attitudes. The standard IAT requires contrasting target categories and the resultant score is a relative measure of associations between the categories (Nosek, Greenwald, \& Banaji, 2007). The choice of an appropriate contrast to the object or concept of interest is critical but straightforward for many research questions, but for others it can be more difficult (Karpinski \& Steinman, 2006). 
In our study, the categories were 'Exercise' and 'Not Exercise' and we chose category exemplars that were unambiguously images of people either exercising or not exercising. The nature of the IAT means that the obtained scores do not indicate the absolute strength of associations with exercise but the strength of associations relative to the strength of associations with the contrast category. For this reason, Dimmock and Banting (2009) suggested that implicit judgments of exercise are likely to be difficult using the IAT, although Banting et al. (2009) successfully employed a standard IAT with the categories 'Exercise' and 'Sedentary' in their study of implicit and explicit exercise schemas, albeit using words rather than images as target exemplars. Notwithstanding these issues, in the current study the IAT scores were highly reliable, sensitive to the experimental manipulation and, importantly from a validity perspective, there was a large effect for differences in exercise status, even though the less frequent exercisers were quite active. Thus, we believe that our interpretations of the observed IAT effects are valid. Nevertheless, it would be worthwhile to determine whether the results are replicable using alternative implicit measures which do not require a contrasting target category, such as the Go/No go Association Task or the Single Category IAT (Karpinski \& Steinman, 2006). A final limitation is that all participants completed the IAT before the explicit measures, thus order effects cannot be ruled out. A meta-analysis of IAT studies by Hofmann et al. (2005a), found no effect of the ordering of implicit and explicit measures, although they did not examine order effects following an experimental manipulation.

\section{Conclusions}

This is the first study to demonstrate that implicit attitudes to exercise can be modified. Although this is of theoretical interest, only immediate effects were assessed and these are likely to be transient. Thus, the applied implications of this finding per se may be somewhat limited. Nevertheless, taken together with the emerging research on the potential benefits of imagery for promoting physical activity, the finding offers promising new avenues for further research 
assessing the impact of imagery interventions on implicit cognitions that could augment efforts to facilitate exercise participation. A pressing need is to assess the generalisability of the effect in less active populations to ensure that positive implicit attitudes can be elicited among those likely to have more negative automatic associations with exercise. Further research is also required to determine whether the activation of positive automatic evaluations through imagery immediately prior to exercising can make the experience of exercise more enjoyable, and whether repeated imagery can produce longer term incremental changes in underlying associative structures with the aim of facilitating sustained participation in exercise. 


\section{References}

Ajzen, I. (1985). From intentions to actions: A theory of planned behaviour. In J. Kuhl \& J. Beckmann (Eds.) Action control: From cognition to behaviour (pp. 11-39). Berlin: Springer-Verlag.

Andersson, E., \& Moss, T. (2011). Imagery and implementation intention: A randomised controlled trial of interventions to increase exercise behaviour in the general population. Psychology of Sport and Exercise, 12, 63-70. http://dx.doi.org/10.1016/j.psychsport.2010.07.004.

Banting, L.K., Dimmock, J.A., \& Lay, B.S (2009). The role of implicit and explicit components of exerciser self-schema in the prediction of exercise behaviour. Psychology of Sport and Exercise, 10, 80-86. http://dx.doi.org/10.1016/j.psychsport.2010.07.00410.1080/17509840802657337.

Bargh, J.A. (1994). The four horsemen of automaticity: Awareness, efficiency, intention and control in social cognitions. In R.S. Wyer \& T.K. Srull (Eds.), Handbook of social cognition (2nd ed., pp. 1-40), Hillsdale, NJ: Erlbaum.

Bargh, J.A., \& Chartrand, T.L. (1999). The unbearable automaticity of being. American Psychologist, 54, 462-479. psycnet.apa.org/doi/10.1037/0003-066X.54.7.462.

Berry, T.R, Spence, J.C., \& Clark, M.E. (2011). Exercise is in! Implicit exercise and sedentarylifestyle bias held by in-groups. Journal of Applied Social Psychology, 41, 2985-2998. http://dx.doi.org/10.1111/j.1559-1816.2011.00857.x.

Biondolillo, M.J., \& Pillemer, D.B. (2014, Feb 26). Using memories to motivate future behaviour: An experimental exercise intervention. Memory, 1-13. http://dx.doi.org/10.1080/09658211.2014.889709. 
Blair, I.V., Ma, J.E., \& Lenton, A.P. (2001). Imagining stereotypes away: The moderation of implicit stereotypes through mental imagery. Journal of Personality and Social Psychology, 81, 828-841. http://psycnet.apa.org/doi/10.1037/0022-3514.81.5.828.

Calitri, R., Lowe, R., Eves, F. F., \& Bennett, P. (2009). Associations between visual attention, implicit and explicit attitude, and behaviour for physical activity. Psychology and Health, 9, 1105-1123. http://dx.doi.org/10.1080/08870440802245306.

Chan, C. K., \& Cameron, L. D. (2012). Promoting physical activity with goal-oriented mental imagery: A randomized controlled trial. Journal of Behavioural Medicine, 35, 347-363. http://dx.doi.org/10.1007/s10865-011-9360-6.

Conner, M.T., Perugini,M., O'Gorman, R., Ayres, K., \& Prestwich, A. (2007). Relations between implicit and explicit measures of attitudes and measures of behaviour: Evidence of moderation by individual difference variables. Personality and Social Psychology Bulletin, 33, 1727-1740. http://dx.doi.org/10.1177/0146167207309194.

Conroy, D.E., Hyde, A.L., Doerksen, S.E., \& Ribeiro, N.F. (2010). Implicit attitudes and explicit motivation prospectively predict physical activity. Annals of Behavioral Medicine, 39, 112-118. http://dx.doi.org/1007/s12160-010-9161-0.

Courneya, K.S., \& Bobick, T.M. (2000). Integrating the theory of planned behaviour with processes and stages of change in the exercise domain. Psychology of Sport and Exercise, 1, 41-56. http://dx.doi.org/10.1016/S1469-0292(00)00006-6.

Courneya, K.S., Conner, M., \& Rhodes, R.E. (2006). Effects of different measurement scales on the variability and predictive validity of the 'two-component' model of the theory of planned behaviour in the exercise domain. Psychology and Health, 21, 557-570. http://dx.doi.org/10.1080/14768320500422857.

Dasgupta, N., \& Greenwald, A. G. (2001). On the malleability of automatic attitudes: Combating automatic prejudice with images of admired and disliked individuals. Journal of 
Personality and Social Psychology, 81,800-814. http://psycnet.apa.org/doi/10.1037/0022$\underline{3514.81 .5 .800 .}$.

Dimmock, J.A. \& Banting, L.K. (2009). The influence of implicit cognitive processes on physical activity: How the theory of planned behaviour and self-determination theory can provide a platform for our understanding. International Review of Sport and Exercise Psychology, 2, 3-22. http://dx.doi.org/10.1080/17509840802657337.

Duncan, L. R., Hall, C. R., Wilson, P. M., \& Rodgers, W. M. (2012). The use of a mental imagery intervention to enhance integrated regulation for exercise among women commencing an exercise program. Motivation and Emotion, 36, 452-464. http://dx.doi.org/10.1007/s11031-011-9271-4.

Duncan, L. R., Rodgers, W. M., Hall, C. R., \& Wilson, P. M. (2011). The use of imagery interventions to enhance three types of self-efficacy for exercise. Applied Psychology: Health and Well-Being, 3, 107-126. http://dx.doi.org/10.1111/j.1758-0854.2010.01043.x.

Eves, F.,F., Scott, E,J., Hoppé, R., \& French, D.P. (2007). Using the affective priming paradigm to explore the attitudes underlying walking behaviour. British Journal of Health Psychology, 12, 571-585. http://dx.doi.org/10.1348/135910706X153775.

Fazio, R.H. (1990). Multiple processes by which attitudes guide behaviour: The MODE model as an integrative framework. Advances in Experimental Social Psychology, 23, 75-109. http://dx.doi.org/10.1016/S0065-2601(08)60318-4.

Fazio, R.H., Chen, J-M., McDonel, E.C., \& Sherman, S.J. (1982). Attitude accessibility, attitudebehaviour consistency, and the strength of the object-evaluation association. Journal of Experimental Social Psychology, 18, 339-357. http://dx.doi.org/10.1016/0022$\underline{1031(82) 90058-0 .}$. 
Fazio, R.H., \& Zanna, M.P. (1981). Direct experience and attitude-behaviour consistency. In L. Berkowitz (Ed.), Advances in experimental social psychology (Vol. 14, pp. 161-202). New York: Academic Press.

Foroni, F., \& Mayr, U. (2005). The power of a story: New, automatic associations from a single reading of a short scenario. Psychonomic Bulletin \& Review, 12, 139-144. http://dx.doi.org/10.3758/BF03196359.

Gawronski, B., \& Bodenhausen, G. V. (2006). Associative and propositional processes in evaluation: An integrative review of implicit and explicit attitude change. Psychological Bulletin, 132, 692-731. http://psycnet.apa.org/doi/10.1037/0033-2909.132.5.692.

Gawronski, B., \& Sritharan, R. (2010). Formation, change, and conceptualization of mental associations: Determinants and principles of variations in implicit measures. In B. Gawronski \& B.K. Payne (Eds.) A handbook of implicit social cognition: Measurement, theory, and applications (pp. 216-240). New York: The Guilford Press.

Giacobbi Jr., P., Dreisbach, K.A., Thurlow, N.M., Anand, P., \& Garcia, F. (2014). Mental imagery increases self-determined motivation to exercise with university enrolled women: A randomized controlled trial using a peer-based intervention. Psychology of Sport and Exercise, 15, 374-381. http://dx.doi.org/10.1016/j.psychsport.2014.03.004.

Godin, G., \& Shephard, R. J. (1985). A simple method to assess exercise behaviour in the community. Canadian Journal of Applied Sport Sciences, 10, 141-146.

Greenwald, A.G., McGhee, D.E., \& Schartz, J.K.L. (1998). Measuring individual differences in implicit recognition: The Implicit Association Test. Journal of Personality and Social Psychology, 74, 1464-1480. http://psycnet.apa.org/doi/10.1037/0022-3514.74.6.1464.

Greenwald, A.G., Nosek, B.A., \& Banaji, M.R. (2003). Understanding and using the Implicit Association Test: I. An improved scoring algorithm. Journal of Personality and Social Psychology, 85, 197-216. http://psycnet.apa.org/doi/10.1037/0022-3514.85.2.197. 
Hagger, M.S., Chatzisarantis, N., \& Biddle, S.J. (2002). A meta-analytic review of the theories of reasoned action and planned behaviour in physical activity: Predictive validity and the contribution of additional variables. Journal of Sport and Exercise Psychology, 24, 3-32.

Harju, B.L., \& Reed, J.M. (2003). Potential clinical implications of implicit and explicit attitudes within possible exercise selves schemata: A pilot study. Journal of Clinical Psychology in Medical Settings, 10, 201-208. http://dx.doi.org10.1023/A:1025414913130

Hofmann, W., Gawronski, B., Gschwendner, T., Le, H., \& Schmitt, M. (2005a). A meta-analysis on the correlation between the Implicit Association Test and explicit selfreport measures. Personality and Social Psychology Bulletin, 31, 1369-1385. http://dx.doi.org/10.1177/0146167205275613.

Hofmann, W., Gschwendner, T., Nosek, B.A., \& Schmitt, M. (2005b). What moderates implicitexplicit consistency? European Review of Social psychology, 16, 335-390. http://dx.doi.org/10.1080/10463280500443228.

Inquisit 3.0. [Computer software]. (2008). Seattle, WA: Millisecond Software.

Jacobs, D., Ainsworth, B., Hartman, T., \& Leon, A. (1993). A simultaneous evaluation of 10 commonly used physical activity questionnaires. Medicine \& Science in Sports \& Exercise, 25, 81-91.

Karpinski, A., \& Steinman, R. B., (2006). The single category implicit association test as a measure of implicit social cognition. Journal of Personality and Social Psychology, 91, 16-32. http://psycnet.apa.org/doi/10.1037/0022-3514.91.1.16.

Lang, P. J. (1979). A bio-informational theory of emotional imagery. Psychophysiology, 16, 495512. http://dx.doi.org/ 10.1111/j.1469-8986.1979.tb01511.x.

Nosek, B.A., Greenwald, A.G., \& Banaji, M.R. (2007). The implicit association test at age 7: A methodological and conceptual review. In J.A. Bargh (Ed.) Social psychology and the 
unconscious: The automaticity of higher mental processes (pp. 265-292). New York: Psychology Press.

Payne, B.K., \& Gawronski, B. (2010). A history of implicit social cognition: Where is it coming from? Where is it now? Where is it going? In B. Gawronski \& B.K. Payne (Eds.) A handbook of implicit social cognition: Measurement, theory, and applications (pp. 1-15). New York: The Guilford Press.

Rydell, R.J., \& McConnell, A.R. (2010). Consistency and inconsistency in implicit cognition. In B. Gawronski \& B.K. Payne (Eds.) A handbook of implicit social cognition: Measurement, theory, and applications (pp. 295-310). New York: The Guilford Press.

Scott, E.J., Eves, F.F., Hoppé, R., \& French, D.P. (2009).Accessibility of salient beliefs about the outcomes of physical activity. British Journal of Health Psychology, 14, 159-174. http://dx.doi.org/10.1348/135910708X327608.

Stanley, D.M., \& Cumming, J. (2010). Are we having fun yet? Testing the effects of imagery use on the affective and enjoyment responses to moderate exercise. Psychology of Sport and Exercise, 11, 582-590. http://dx.doi.org/10.1016/j.psychsport.2010.06.010.

Strack, F., \& Deutsch, R. (2004). Reflective and impulsive determinants of social behaviour. Personality and Social Psychology Review, 8, 220-247. http://dx.doi.org/10.1207/s15327957pspr0803_1.

Williams, S. E.,, Cooley, S. J., Newell, E., Weibull, F., \& Cumming, J. (2013). Seeing the difference: Advice for developing effective imagery scripts for athletes. Journal of Sport Psychology in Action, 4, 109-121. http://dx.doi.org/10.1080/21520704.2013.781560.

Wilson, T.D., Lindsey, S., \& Schooler, T.Y. (2000). A model of dual attitudes. Psychological Review, 107, 101-126. http://psycnet.apa.org/doi/10.1037/0033-295X.107.1.101. 


\section{APPENDIX}

\section{Exercise imagery script}

Close your eyes and relax. Imagine yourself walking into a gym. Maybe you do not really enjoy exercise and you don't like the idea of going to the gym, but just for now, imagine that you are enjoying it. When you walk through the doors you find that it is brightly lit with many windows. There is music you enjoy playing in the background, along with a gentle hum of exercise equipment and other people. You notice this is a friendly atmosphere. You make your way to the cardio area. Imagine yourself getting onto one of the aerobics machines. You can imagine any type of cardio you want; maybe you are walking on a treadmill, using the elliptical, or riding a bike. Imagine yourself exercising on the cardio equipment and take a moment to feel the sensations going through your body. You can feel your muscles warming up, your lungs becoming stronger, your heart becoming stronger. Aerobic exercise is making you feel invigorated. Imagine that you have just completed your cardio exercise and begin making your way over to the free weights or weight machine area. Choose a strength exercise that you will do. Maybe this is bicep curls, leg press, or even exercises that do not require equipment, such as pushups or sit-ups. Now imagine yourself doing this exercise. As you exercise you can feel your muscles strengthening. You can feel your posture lengthening. Take a moment to imagine how good you feel when you have completed your strength training exercise. Now you head over to the floor mats to stretch. You find a space for yourself and start stretching. As you stretch your muscles you think about how you enjoyed the exercises you did today. Take a moment to notice how you are feeling. You notice that you feel relaxed and focused. You feel satisfied and mentally rejuvenated. You feel you are in control. Imagine yourself leaving the gym, ready to enjoy the rest of the day. You may open your eyes. 


\section{Control imagery script}

Close your eyes and relax. Imagine yourself arriving at home after a busy day. When you walk through the doors you find that it is bright and warm inside. You take off your shoes and put your jacket away. Notice how good it feels to be home. Now, make your way to the kitchen. You are starting to think about what you are going to prepare for dinner. Maybe you do not usually prepare dinner and maybe this is not something you really enjoy doing, but just for now, imagine that you are enjoying it. Take a moment to imagine yourself preparing your favourite meal. Maybe you are boiling water, maybe you are turning on the oven. Imagine what you can see and hear. Smell the food that you are preparing. Preparing your dinner is helping you to relax. You can feel your shoulders loosening. You are starting to unwind after your day. Imagine that you have just completed preparing your meal and are making your way over to a place where you will eat. Maybe this is at a table, maybe it is on the couch. Now imagine yourself tasting the meal you have prepared. As you eat you begin to feel satisfied. You can feel your body relaxing even further. Take a moment to imagine how you feel when you have completed your meal. Now that you have enjoyed your meal it is time to clean up after dinner. Imagine yourself running the water to fill up the sink and pouring in some dish soap. As you wash the dishes feel the warm sensation of the water on your hands. Think about how nice it will be to have the dishes done and put away. With the dishes done you feel a sense of completion and control. You notice that you are starting to feel satisfied and content. Now imagine yourself leaving the kitchen, ready to relax and enjoy the rest of the evening. You may open your eyes. 
Table 1. Exercise frequency by exercise status.

\begin{tabular}{|c|c|c|c|c|c|c|c|c|c|c|c|c|c|c|c|c|}
\hline & \multicolumn{4}{|c|}{$\underline{\text { Total exercise }}$} & \multicolumn{4}{|c|}{ Strenuous exercise } & \multicolumn{4}{|c|}{ Moderate exercise } & \multicolumn{4}{|c|}{ Mild exercise } \\
\hline & \multicolumn{4}{|c|}{$95 \% \mathrm{CI}$} & \multirow[b]{2}{*}{$M$} & \multirow[b]{2}{*}{$S D$} & \multicolumn{2}{|c|}{$95 \% \mathrm{CI}$} & \multirow[b]{2}{*}{$M$} & \multirow[b]{2}{*}{$S D$} & \multicolumn{2}{|c|}{$95 \% \mathrm{CI}$} & \multirow[b]{2}{*}{$M$} & \multirow[b]{2}{*}{$S D$} & \multicolumn{2}{|c|}{$95 \% \mathrm{CI}$} \\
\hline & $M$ & $S D$ & Lo & $\mathrm{Hi}$ & & & Lo & $\mathrm{Hi}$ & & & Lo & $\mathrm{Hi}$ & & & Lo & $\mathrm{Hi}$ \\
\hline Frequent exercisers & 94.66 & 11.26 & 89.99 & 99.45 & 12.50 & 8.82 & 11.07 & 12.93 & 7.88 & 10.27 & 6.15 & 9.60 & 9.26 & 13.02 & 7.13 & 11.40 \\
\hline Less frequent exercisers & 32.58 & 29.07 & 27.79 & 37.36 & 1.58 & 2.83 & 0.15 & 3.00 & 2.46 & 3.75 & 0.74 & 4.19 & 2.64 & 4.06 & 0.50 & 4.77 \\
\hline
\end{tabular}


Table 2. Descriptive statistics for attitude measures by experimental condition and exercise status.

\begin{tabular}{|c|c|c|c|c|c|c|c|c|c|c|c|c|}
\hline & \multicolumn{4}{|c|}{$\underline{\text { IAT } D \text {-score }}$} & \multicolumn{4}{|c|}{ Instrumental Attitude } & \multicolumn{4}{|c|}{ Affective Attitude } \\
\hline & \multirow[b]{2}{*}{$M$} & \multicolumn{3}{|c|}{$95 \% \mathrm{CI}$} & \multirow{2}{*}{$M$} & \multicolumn{3}{|c|}{$95 \% \mathrm{CI}$} & \multirow[b]{2}{*}{$M$} & \multicolumn{3}{|c|}{$95 \% \mathrm{CI}$} \\
\hline & & $S D$ & Lo & $\mathrm{Hi}$ & & $S D$ & Lo & $\mathrm{Hi}$ & & $S D$ & Lo & $\mathrm{Hi}$ \\
\hline \multicolumn{13}{|c|}{ Exercise Imagery Condition } \\
\hline Frequent exercisers & 0.78 & 0.53 & 0.61 & 0.96 & 6.73 & 0.42 & 6.51 & 6.95 & 6.08 & 0.66 & 5.81 & 6.35 \\
\hline Less frequent exercisers & 0.50 & 0.54 & 0.31 & 0.68 & 5.79 & 0.79 & 5.57 & 6.01 & 4.72 & 0.98 & 4.45 & 4.99 \\
\hline Total group & 0.65 & 0.55 & 0.51 & 0.77 & 6.26 & 0.79 & 6.10 & 6.41 & 5.40 & 1.07 & 5.21 & 5.59 \\
\hline \multicolumn{13}{|l|}{ Control Imagery Condition } \\
\hline Frequent exercisers & 0.60 & 0.62 & 0.42 & 0.78 & 6.78 & 0.36 & 6.56 & 6.95 & 5.96 & 0.67 & 5.69 & 6.23 \\
\hline Less frequent exercisers & 0.22 & 0.57 & 0.03 & 0.40 & 6.18 & 1.02 & 5.57 & 6.01 & 5.01 & 1.08 & 4.74 & 5.28 \\
\hline Total group & 0.41 & 0.63 & 0.28 & 0.54 & 6.48 & 0.82 & 6.32 & 6.63 & 5.48 & 1.01 & 5.29 & 5.68 \\
\hline \multicolumn{13}{|l|}{$\underline{\text { Exercise Status }}$} \\
\hline Frequent & 0.69 & 0.58 & 0.57 & 0.82 & 6.75 & 0.39 & 6.60 & 6.91 & 6.02 & 0.66 & 5.82 & 6.21 \\
\hline Less Frequent & 0.36 & 0.57 & 0.23 & 0.49 & 5.98 & 0.81 & 5.83 & 6.12 & 4.87 & 1.03 & 4.67 & 5.06 \\
\hline
\end{tabular}

